\title{
Process Parameters Optimization of Multiple Quality Characteristics in Plastic Injection Molding Using BPNN and GA
}

\author{
Wen-Chin Chen and Shi-Bo Lin
}

\begin{abstract}
This paper presents an optimization approach to find optimal process parameters of multiple quality characteristics in plastic injection molding (PIM). Melt temperature, injection velocity, packing pressure, packing time, and cooling time are selected as process parameters in the experiment. Besides, product length and warpage are chosen as multiple quality characteristics. Taguchi orthogonal array is firstly conducted in the experiment and the experimental data are employed to calculate the signal-to-noise $(\mathrm{S} / \mathrm{N})$ ratio. Analysis of variance (ANOVA) is then used to find the best combination of parameter settings for product length and warpage. In addition, BPNN is used to construct an $\mathrm{S} / \mathrm{N}$ ratio predictor. Then, the $S / N$ ratio predictor is associated with GA to obtain the optimal process parameter. Finally, two confirmation experiments are taken to exam the effectiveness of proposed approach. Experimental results show that the proposed optimization approach not only can satisfy the quality characteristics, but also can improve process stability.
\end{abstract}

Index Terms-ANOVA, BPNN, GA, injection molding, taguchi method.

\section{INTRODUCTION}

Injection molding is commonly used to produce plastic product, because it can produce large amount of product in very short time with a low production cost. Moreover, several advantages such as short cycle time production, light weight, and high surface quality, makes plastic injection molding (PIM) as a solution for industries to survive in the competitive world. However, besides these advantages, PIM is a more complex process than it is thought to be. Inappropriate mold design, material and parameter settings will produce defects in the plastic parts. Many researchers investigate defects in PIM, such as warpage, shrinkage, sink marks, short shot and so on [1]-[4]. Well-controlled parameter setting is one of the solutions to avoid or reduce these defects. Previously, process parameters in PIM process relied on the technician's experience using a trial-and-error approach. However, this approach is not effective and unsuitable for complex manufacturing processes. Then, many studies used the Taguchi method to determine the combination of process parameters for improving product quality [5], [6]. However, Taguchi method is not suitable to find the optimal parameter settings for continuous value and it has difficulties when used for multiple response process

Manuscript received October 15, 2013; revised December 20, 2013.

Wen-Chin Chen and Shi-Bo Lin are with the Department of Industrial Management, Chung-Hua University, No. 707, Sec. 2, Wu Fu Rd., Hsinchu, Taiwan (e-mail: wenchin@chu.edu.tw,m10121020@chu.edu.tw). parameters design problem [7]. In Ozcelik and Erzurumlu research, warpage of thin shell plastic part was successfully reduced over $40 \%$ using combination of DOE, RSM, FEA and GA. [8] Yin et al. presented reduction of warpage value by $32.9 \%$ using the BPNN and finite element analysis (FEA). [9] In their study, they state that process parameters can be optimized with help of prediction system, where BPNN was used to predict the relationship between parameter settings and warpage value. [10]-[13]

According to previous studies, many researchers only focused on optimizing quality in PIM using various methods, but they did not asses the stability of the process. Therefore, this study pays attention to both the product quality and the process stability.

\section{Proposed APPROACH}

This study proposes an optimization approach for multiple-input multiple-output (MIMO) in plastic injection molding. Melt temperature, injection velocity, packing pressure, packing time, and cooling time are selected as process parameters in the experiment. Product length and warpage are chosen as multiple responses. Experimental work is conducted using Taguchi orthogonal array. Experimental data are employed to compute the signal-to-noise $(\mathrm{S} / \mathrm{N})$ ratio, and ANOVA is used to find the best parameter settings. In addition, the $\mathrm{S} / \mathrm{N}$ ratio predictor is constructed using BPNN. Then, $\mathrm{S} / \mathrm{N}$ ratio predictor and GA are used to find optimal process parameters. Target length for product length is $170.5 \mathrm{~mm}$ and minimal warpage values are the objective of the product quality in this study.

\section{EXPERIMENTAL RESULTS AND ANALYSIS}

\section{A. Experimental Equipment}

This section presents an illustrative sequence of implementation of experimental work for process parameters optimization under five parameter settings and two quality responses of the proposed approach. The proposed plastic product is a rear cover of a printer part as shown in Fig. 1 and Fig. 2. The target value of quality responses are $170.5 \mathrm{~mm}$ for length and lower value for warpage. Warpage value is recorded using laser measurement along the middle side of the parts (at the same side as measuring the length).

\section{B. Implementation of Taguchi Method and ANOVA}

The Taguchi orthogonal array $\mathrm{L}_{25}\left(5^{6}\right)$ is selected in this study. The control factors, variables and levels, are shown in 
Table I. There are 25 treatments for all combinations for five factors and five levels. Five replications are used for each setting to increase the sensitivity of statistical analysis. Therefore, totally 125 sample data and 25 test data are collected for the $\mathrm{L}_{25}\left(5^{6}\right)$ design. In addition, another five treatments for different settings are selected in this experiment and later will be used as testing data for BPNN. Nominal-the-best and smaller-the-better are used as the formulation to calculate $\mathrm{S} / \mathrm{N}$ ratio of product length and warpage, respectively. The highest value of $\mathrm{S} / \mathrm{N}$ ratio is determined as optimal initial parameter setting. Therefore, the treatment no. 4 is selected as initial parameter for product length, since it has the highest value of $\mathrm{S} / \mathrm{N}$ ratio (36.696) for product length. In addition, the treatment no.22 (26.313) is selected as the optimal initial parameter setting for warpage. The purpose of ANOVA analysis it to determine the significant factors affecting product's length and warpage from the experiment. By using P-value smaller than 0.05 as the threshold, the significant factors of warpage are packing time and cooling time. Vice versa, melt temperature, injection velocity, and packing pressure are considered not significant. The result of ANOVA analysis for product length and warpage is shown in Table II and Table III, respectively. According to the significance in the factors between the quality characteristics from the results of the ANOVA analysis, both quality characteristics with significant and insignificant factors adopt the average value as the optimal Taguchi factor level. For one of the quality with significant and insignificant factor, the level of significance is taken as the optimal factor. The initial parameter settings for highest $\mathrm{S} / \mathrm{N}$ ratio for product length and warpage are shown in Table III and Table IV.

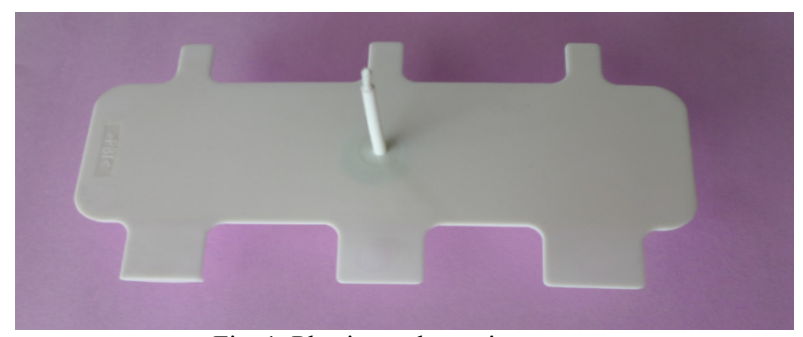

Fig. 1. Plastic product printer part.

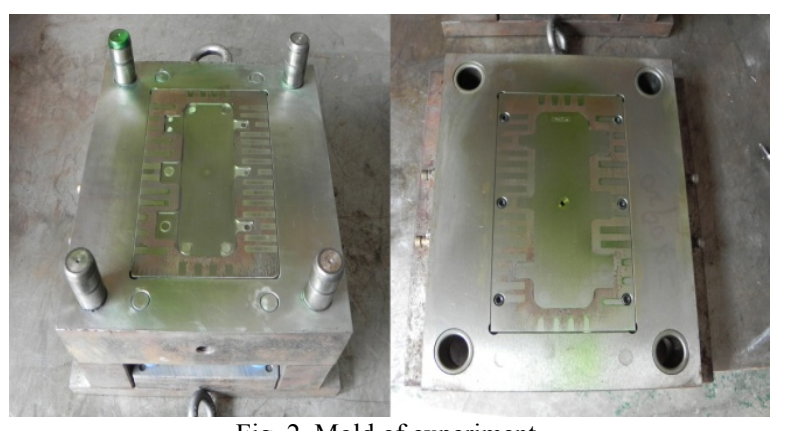

Fig. 2. Mold of experiment.

TABLE I: TAGUCHI ORTHOGONAL ARRAY $\mathrm{L}_{25}\left(5^{6}\right)$

\begin{tabular}{ccccccc}
\hline \hline \multirow{2}{*}{ Parameter } & \multirow{2}{*}{ Variable } & \multicolumn{5}{c}{ Levels } \\
\cline { 3 - 7 } & & 1 & 2 & 3 & 4 & 5 \\
\hline \multirow{2}{*}{ Melt temperature $\left({ }^{\circ} \mathrm{C}\right)$} & $x_{1}$ & 24 & 25 & 25 & 25 & 26 \\
& & 9 & 2 & 5 & 8 & 1 \\
\hline Injection velocity $(\mathrm{mm} / \mathrm{s})$ & $x_{2}$ & 30 & 34 & 38 & 42 & 46 \\
\hline Packing pressure $(\mathrm{MPa})$ & $x_{3}$ & 27 & 31 & 35 & 39 & 43 \\
\hline Packing time $(\mathrm{s})$ & $x_{4}$ & 0.9 & 1.2 & 1.5 & 1.8 & 2.1 \\
\hline Cooling time $(\mathrm{s})$ & $x_{5}$ & 11 & 14 & 17 & 20 & 23 \\
\hline \hline
\end{tabular}

TABLE II: INITIAL PARAMETER SETTINGS FOR HIGHEST S/N RATIO FOR LENGTH AND WARPAGE

\begin{tabular}{ccccccccc}
\hline \hline $\begin{array}{c}\text { Parameter } \\
\text { variable }\end{array}$ & $x_{1}$ & $x_{2}$ & $x_{3}$ & $x_{4}$ & $x_{5}$ & $\begin{array}{c}\text { Highest } \\
\text { r ratio } \\
\text { for } \\
\text { length }\end{array}$ & $\begin{array}{c}\text { Highest } \\
\text { S/N ratio } \\
\text { for } \\
\text { warpage }\end{array}$ \\
\hline $\begin{array}{c}\text { Parameter } \\
\text { combination }\end{array}$ & 249 & 42 & 39 & 1.8 & 20 & 36.696 & \\
\cline { 2 - 8 }
\end{tabular}

TABLE III: ANOVA ANALYSIS FOR LENGTH

\begin{tabular}{ccccccc}
\hline $\begin{array}{c}\text { Source } \\
\text { of } \\
\text { variance }\end{array}$ & DF & Seq SS & Adj SS & Adj MS & F & p-value \\
\hline$x 1$ & 4 & $\begin{array}{c}0.03455 \\
5\end{array}$ & $\begin{array}{c}0.03455 \\
5\end{array}$ & $\begin{array}{c}0.00863 \\
9\end{array}$ & 3.50 & 0.126 \\
\hline$x 2$ & 4 & $\begin{array}{c}0.01158 \\
2\end{array}$ & $\begin{array}{c}0.01158 \\
2\end{array}$ & $\begin{array}{c}0.00289 \\
5\end{array}$ & 1.17 & 0.441 \\
\hline$x 3$ & 4 & $\begin{array}{c}0.06034 \\
7\end{array}$ & $\begin{array}{c}0.06034 \\
7\end{array}$ & $\begin{array}{c}0.01508 \\
7\end{array}$ & 6.11 & 0.054 \\
\hline$x 4$ & 4 & $\begin{array}{c}0.23880 \\
9\end{array}$ & $\begin{array}{c}0.23880 \\
9\end{array}$ & $\begin{array}{c}0.05970 \\
2\end{array}$ & 24.1 & 0.005 \\
\hline$x 5$ & 4 & $\begin{array}{c}0.25538 \\
7\end{array}$ & $\begin{array}{c}0.25538 \\
7\end{array}$ & $\begin{array}{c}0.06384 \\
7\end{array}$ & 25.8 & 0.004 \\
\hline Error & 4 & $\begin{array}{c}0.00988 \\
4\end{array}$ & $\begin{array}{c}0.00988 \\
4\end{array}$ & $\begin{array}{c}0.00247 \\
1\end{array}$ & & \\
\hline Total & 24 & $\begin{array}{c}0.61056 \\
3\end{array}$ & & & & \\
\hline
\end{tabular}

TABLE IV: ANOVA ANALYSIS FOR LENGTH

\begin{tabular}{ccccccc}
\multicolumn{7}{c}{ TABLE IV: ANOVA ANALYSIS FOR LENGTH } \\
\hline $\begin{array}{c}\text { Source } \\
\text { of variance }\end{array}$ & DF & Seq SS & Adj SS & Adj MS & F & p-value \\
\hline$x 1$ & 4 & $\begin{array}{c}0.6246 \\
6\end{array}$ & $\begin{array}{c}0.6246 \\
6\end{array}$ & $\begin{array}{c}0.1561 \\
6\end{array}$ & 5.53 & 0.063 \\
\hline$x 2$ & 4 & $\begin{array}{c}0.2190 \\
8\end{array}$ & $\begin{array}{c}0.2190 \\
8\end{array}$ & $\begin{array}{c}0.0547 \\
7\end{array}$ & 1.94 & 0.269 \\
\hline$x 3$ & 4 & $\begin{array}{c}0.5759 \\
3\end{array}$ & $\begin{array}{c}0.5759 \\
3\end{array}$ & $\begin{array}{c}0.1439 \\
8\end{array}$ & 5.1 & 0.072 \\
\hline$x 4$ & 4 & $\begin{array}{c}1.6822 \\
3\end{array}$ & $\begin{array}{c}1.6822 \\
3\end{array}$ & $\begin{array}{c}0.4205 \\
6\end{array}$ & 14.8 & 0.011 \\
\hline$x 5$ & 4 & $\begin{array}{c}1.0065 \\
3\end{array}$ & $\begin{array}{c}1.0065 \\
3\end{array}$ & $\begin{array}{c}0.2516 \\
3\end{array}$ & 8.91 & 0.029 \\
\hline Error & 4 & $\begin{array}{c}0.1130 \\
3\end{array}$ & $\begin{array}{c}0.1130 \\
3\end{array}$ & $\begin{array}{c}0.0282 \\
6\end{array}$ & & \\
\hline Total & 24 & $\begin{array}{c}4.2214 \\
5\end{array}$ & & & & \\
\hline
\end{tabular}

\section{Optimization Model}

The optimization constructed using combination of $\mathrm{S} / \mathrm{N}$ ratio predictor $\left(\mathrm{BPNN}_{\mathrm{SN}}\right)$ and genetic algorithm.

Twenty-five treatments from the Taguchi experiment are used as training data and the rest is used as testing data for $\mathrm{BPNN}_{\mathrm{SN}}$. A program writting in MATLAB 2007 software is used to train and test the network. Five control factors (melt temperature, injection velocity, packing pressure, packing time and cooling time) are used as input. $\mathrm{S} / \mathrm{N}$ ratio for product length and warpage are used as output responses of BPNN. BPNN has a hidden layer and contains 7 neurons. The range of normalization is from 0.1 to 0.9 . Moreover, sigmoid function is used for the activation function. The training and testing performances (RMSE) of $\mathrm{BPNN}_{\mathrm{SN}}$ are 0.0032 and 0.0708 , respectively. The fitness function of genetic algorithm for the optimization is shown as follows:

$$
\begin{aligned}
& \operatorname{Min} F(X)=\left(Y_{i}-36.696\right)^{2}+\left(Y_{w}-26.313\right)^{2} \\
& \text { s.t. } \\
& 249 \leq x_{1} \leq 261,32 \leq x_{2} \leq 44,27 \leq x_{3} \leq 41, \\
& 1.65 \leq x_{4} \leq 2.10,17 \leq x_{5} \leq 23
\end{aligned}
$$

where $F(X)$ is the fitness function; $Y_{l}$ and $Y_{w}$ are predicted $\mathrm{S} / \mathrm{N}$ 
ratios for length and warpage, respectively. Then, in the genetic algorithm is associated with $\mathrm{S} / \mathrm{N}$ ratio predictor. The initial process parameter settings (initial population) for using in GA search approach is 255 for $\mathrm{x}_{1}, 38$ for $\mathrm{x}_{2}, 33$ for $\mathrm{x}_{3}$, 1.95 for $\mathrm{x}_{4}$ and 20 for $\mathrm{x}_{5}$. Being a critical factor in search results of GA, the parameter comprise the following items to be configured. For the restrictive ranges of variables applicable to optimized search, the features of our variables in operations comprise size of a mating pool is 100 , the crossover method is single point, the crossover rate is 0.8 , the mutation method is single point, the mutation rate is 0.6 , the threshold for convergence is $1.000 \mathrm{e}-006$ or iteration of 10000 generations. After numerical analysis, the optimal parameters, $x_{1}, x_{2}, x_{3}, x_{4}$ and $x_{5}$, are 257, 41, 42, 2 and 18.5, respectively.

\section{Confirmation Experiment}

Two confirmation experiments were conducted to assess the effectiveness of these methods. According to the experimental results from 25 product samples, standard deviation for length of the optimization is 0.0150 and the Taguchi method is 0.0161 . Warpage of the Taguchi method is 0.0462 . The proposed approach also has the most stable quality for warpage $(0.0258)$. In addition, the process capability index $\left(C_{p k}\right)$ value of the optimization is 2.77 and Taguchi method is 1.41 . The proposed optimization approach successfully finds optimal parameter settings which not only satisfy the quality specification, but also improve stability of the PIM process.

\section{CONCLUSION}

Determination of optimal process parameter settings is a critical work that influences the capacity, quality, and cost of product manufacture. Engineers have conventionally used trial-and-error processes or Taguchi's process parameter design method to determine the final optimal process parameter settings. However, the application of these methods has some shortcomings and may cause engineers to make undesirable final optimal process parameter settings. This research proposes an effective process parameter optimization approach that integrates Taguchi's parameter design method, back-propagation neural network, genetic algorithms, and engineering optimization concepts. The proposed approach can effectively solve the flaw in the Taguchi method, which yields the global optimum while utilizing genetic algorithm to break away from local optimum. The experimental results support the proposed approach which not only enhances the stability of the entire injection molding process but also improves the quality characteristics, the length and warpage. According to the experiment results, the proposed approach is feasible and effective for process parameter optimization in plastic injection molding and can assist the manufacturing industry in achieving competitive advantages on quality and cost.

\section{ACKNOWLEDGEMENT}

The research is conducted as part of a project sponsored by Polyprecision Industrial Co. Ltd., Hsinchu, Taiwan.

\section{REFERENCES}

[1] J. J. Mostafa, M. A. Mohammad, and M. Ehsan, “A hybrid response surface methodology and simulated annealing algorithm: A case study on the optimization of shrinkage and warpage of a fuel filter," in Proc. International Conf. on Computer Communication and Management, Singapore, vol. 13, no. 10, 2011, pp. 2156-2163.

[2] H. Oktem, "Optimum process conditions on shrinkage of an injected-molded part of DVD-ROM cover using Taguchi robust method," International Journal of Advanced Manufacturing Technology, vol. 61, no. 5-8, pp. 519-528, July 2011.

[3] D. Kusi, T. Kek, J. M. Slabe, R. Svečko, and J. Grum, "The impact of process parameters on test specimen deviations and their correlation with AE signals captured during the injection molding cycle," Polymer Testing, vol. 32, pp. 583-593, May 2013.

[4] X. Wang, G. Zhao, and G. Wang, "Research on the reduction of sink mark and warpage of the molded part in rapid heat cycle molding process," Materials and Design, vol. 47, pp. 779-792, May 2013.

[5] M. Altan, "Reducing shrinkage in injection moldings via the Taguchi, ANOVA and neural network methods," Materials and Design, vol. 31, no. 1, pp. 599-604, January 2010.

[6] C. F. Ng, S. Kamaruddin, A. N. Siddiquee, and Z. A. Khan, "Experimental investigation on the recycled HDPE and optimization of injection molding process parameters via Taguchi method," International Journal of Mechanical and Materials Engineering, vol. 6, no. 1, pp. 81-91, 2011.

[7] G. Xu, F. Deng, and Y. Xu, "Adaptive particle swarm optimization-based neural network in quality prediction for plastic injection molding," Journal of Computational Information Systems, vol. 7, no. 2, pp. 462-470, 2011.

[8] B. Ozcelik and T. Erzurumlu, "Determination of effecting dimensional parameters on warpage of thin shell plastic parts using integrated response surface method and genetic algorithm," International Communications in Heat and Mass Transfer, vol. 32, no. 8, pp. 1085-1094, August 2005.

[9] F. Yin, H. Mao, L. Hua, W. Guo, and M. Shu, "Back propagation neural network modeling for warpage prediction and optimization of plastic products during injection molding," Materials and Design, vol. 32, no. 4, pp. 1844-1850, April 2011.

[10] L. Idoumghar, M. Melkemi, R. Schott, and M. I. Aouad, "Hybrid PSO-SA type algorithms for multimodal function optimization and reducing energy consumption in embedded systems," Applied Computational Intelligence and Soft Computing, pp. 1-12, 2011.

[11] Y. Zhang and L. Wu, "A robust hybrid restarted simulated annealing particle swarm optimization technique," Advances in Computer Science and its Applications, vol. 1, no. 1, pp. 5-8, 2012.

[12] W. C. Chen, G. L. Fu, and D. Kurniawan, "A two-stage optimization system for the plastic injection molding with multiple performance characteristics," Advanced Materials Research, vol. 468-471, no. 386-390, February 2012.

[13] E. Reséndiz, and C. A. Rull-Flores, "Mahalanobis-Taguchi system applied to variable selection in automotive pedals components using Gompertz binary particle swarm optimization," Expert Systems with Application, vol. 40, pp. 2361-2365, June 2013.

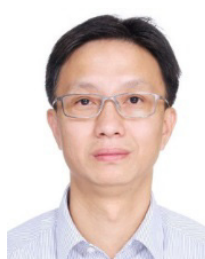

Wen-Chin Chena received the Ph.D. degree in mechanical engineering from University of Florida, USA, in 1995. He is a Professor of Industrial Management at Chung-Hua University, Hsinchu, Taiwan. He has published papers in neural computing and applications, International Journal of Advanced Manufacturing Technology, Mathematical Problems in Engineering, Expert Systems with Applications, Technovation, Applied Economics Letters, International Journal of Heat and Mass Transfer, and Journal of Heat Transfer, ASME. His research areas include Optimization Control in Engineering, Advanced Process control, Automation, and Performance Assessment.

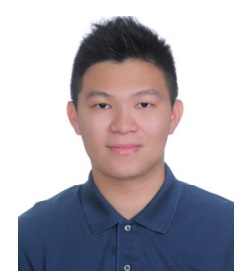

Shi-Bo Lin was born on 7 June 1990 in Chiayi County 604, Taiwan (R.O.C.). He received the bachelor degree in industrial management on June, 2012. Nowadays, He enrolled in the M.S. program, and his undergraduate and graduate programs are both at Chung-Hua University in Taiwan. During the graduate school period, he is a research assistant. His research fields are Engineering Optimization and Quality

Management. In addition, he is a student member of the Chinese Institute of Industrial Engineers. 